\title{
Diabetic Foot in Algeria - Illustration III Gangrene of the Extremities in Covid 19
}

\author{
Nadia Boudjenah* \\ Diabetic Foot Centre, Algeria
}

*Corresponding author: Nadia Boudjenah, Diabetic Foot Centre, 132 route Ouled Fayet, Amara, Chéraga, Alger 16003, Tel: 213555

0389 88, Algeria

To Cite This Article: Nadia Boudjenah. Diabetic Foot in Algeria - Illustration III Gangrene of the Extremities in Covid 19. Am J Biomed Sci \& Res. 2021 - 14(1). AJBSR.MS.ID.001949. DOI: 10.34297/AJBSR.2021.14.001949.

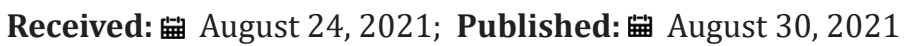

\begin{abstract}
Diabetic Foot in Algeria - Gangrene of The Extremities During Covid 19", a question often came up: were there only amputations in the cases encountered?

We provide an answer through this illustration of 3 cases, including the most recent, since unfortunately the pandemic continues.

Our therapeutic strategy is fully described in another article "Diabetic Foot in Algeria - Carbomedtherapy".

The type of debridement that we have chosen is described in another article "Diabetic Foot in Algeria - Debridement of Wounds - Our Attitude" and illustrated in "Diabetic Foot in Algeria - Illustration II"
\end{abstract}

\section{Patient 1}

Patient: N.... S

a. Male

b. Age: 60 years old

c. Type 2 diabetic on insulin

d. Without particular health history

e. No kidney failure

f. Put under Aspegic 100 and Lovenox 0.6 (2 x per day) for 1 month.

g. HbA1c: $9.20 \%$

h. White blood cells $21000 / \mathrm{mm}^{3}$

i. Anemia

j. Platelet count at $531,000 / \mathrm{mm}^{3}$ requiring discontinuation of Lovenox

k. Neuropathy of the 4 limbs

l. COVID 19 that required hospitalization the previous month.
Visit for necrosis of the left forefoot.

Patient tired from a long hospitalization following COVID 19, infected and anemic with a significant imbalance of his diabetes and very stressed by the news of the major amputation.

We decided to start the treatment while clarifying the risk of major amputation.

\section{Treatment}

Lab analyses and other medical tests:

Arterial and venous Echodoppler which revealed, in addition to significant Médiacalcose

\section{At the level of the lower left limb:}

a. incomplete distal thrombosis in the superficial femoral artery

b. incomplete thrombosis in the popliteal artery

c. incomplete segmental thrombosis in places in the posterior tibial artery.

d. significant stenosis thrombotic in places in the anterior tibial artery 
e. incomplete thrombosis in the proximal pedal artery

\section{In the lower right limb:}

a. incomplete segmental thrombosis in places in the posterior tibial artery

b. incomplete distal segmental thrombosis in the pedal artery.

There is no venous thrombosis

i. PERICAM*

ii. Blood test

iii. Sampling for bacteriological examination.

First session of Carbomedtherapy (Carbon Dioxide Therapy - CDT).

\section{Local care on the left foot:}

a. Foot bath

b. BELCIC* creme first followed by Maggot therapy. c. Use of Leadermax* crème and Maggot Therapy treatment

d. Coconut balm for rehydration

e. Econazole cream for onychomycosis

f. After surgery, ALTRAZEAL* is used in place of BELCIC and Maggot Therapy treatment.

Broad-spectrum antibiotic therapy at the start, targeted later after the results of the antibiogram.

Physical activity: Active mobilization and complete discharge of the left lower limb with anti-edema position of both limbs.

The evolution has been made towards the delineation of the necrosis both on the surface and in depth, which has allowed us to propose a conservative gesture on the left foot.

The surgery act took place on October 09, 2020, a little more than 1 month after the first visit.

The procedure consisted of amputation of the forefoot and skin graft, leaving sufficient plantar support in place.
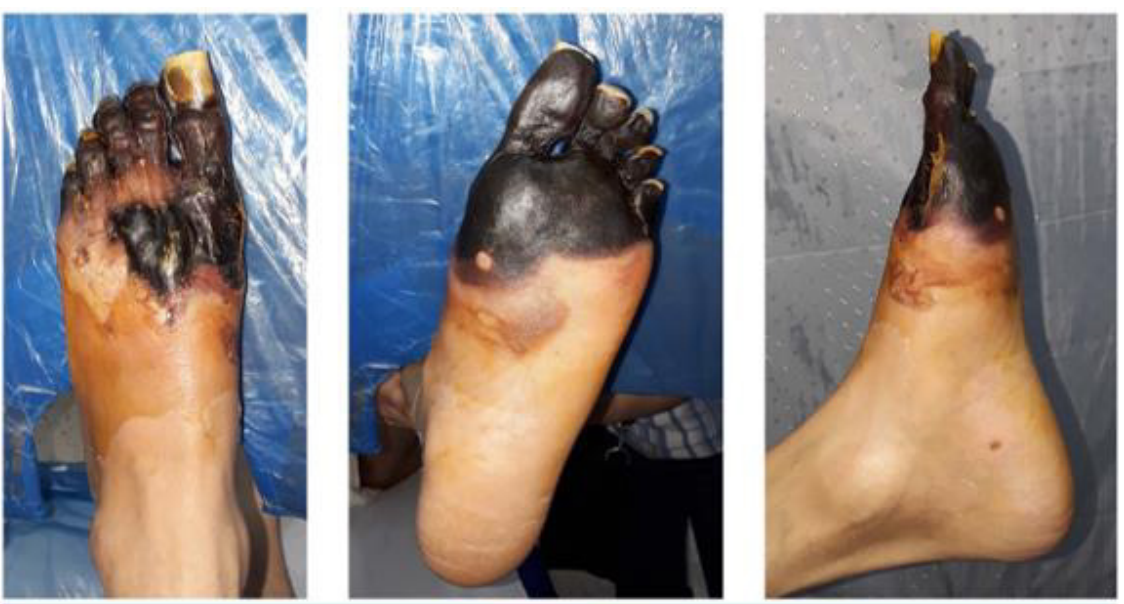

September 05, 2020
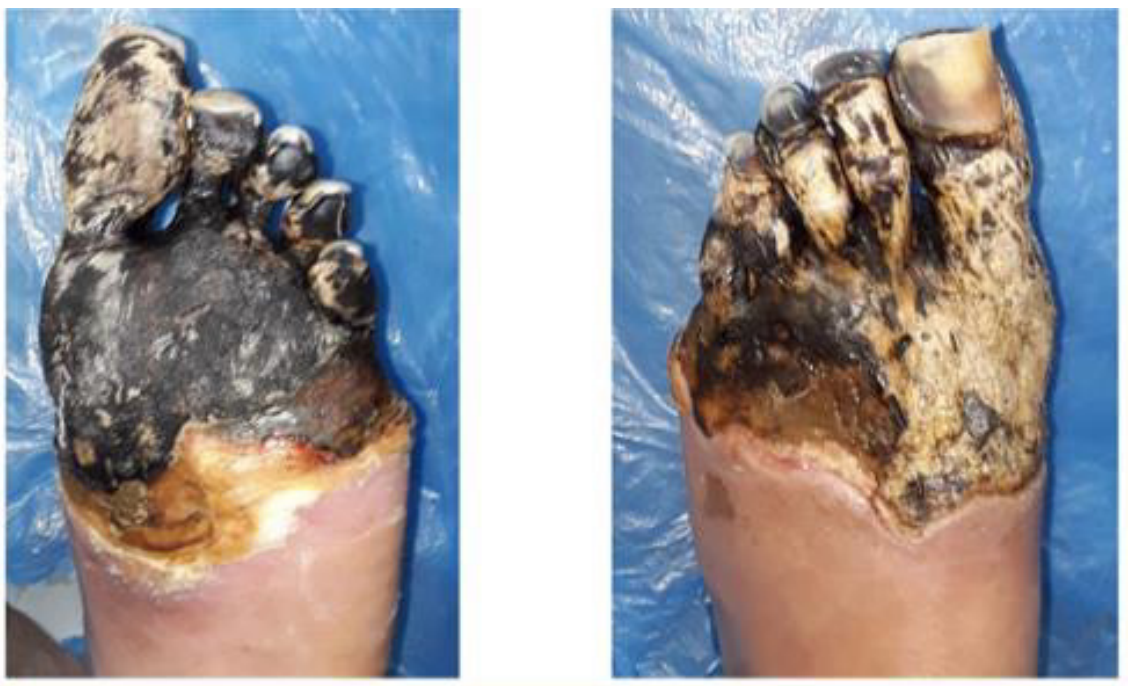

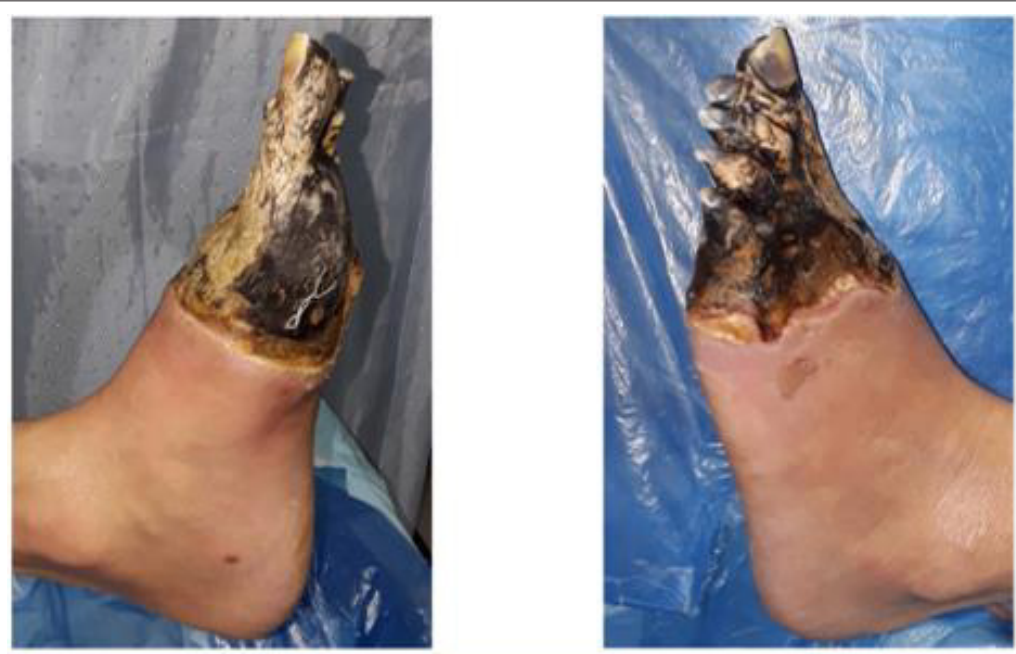

October 05, 2020
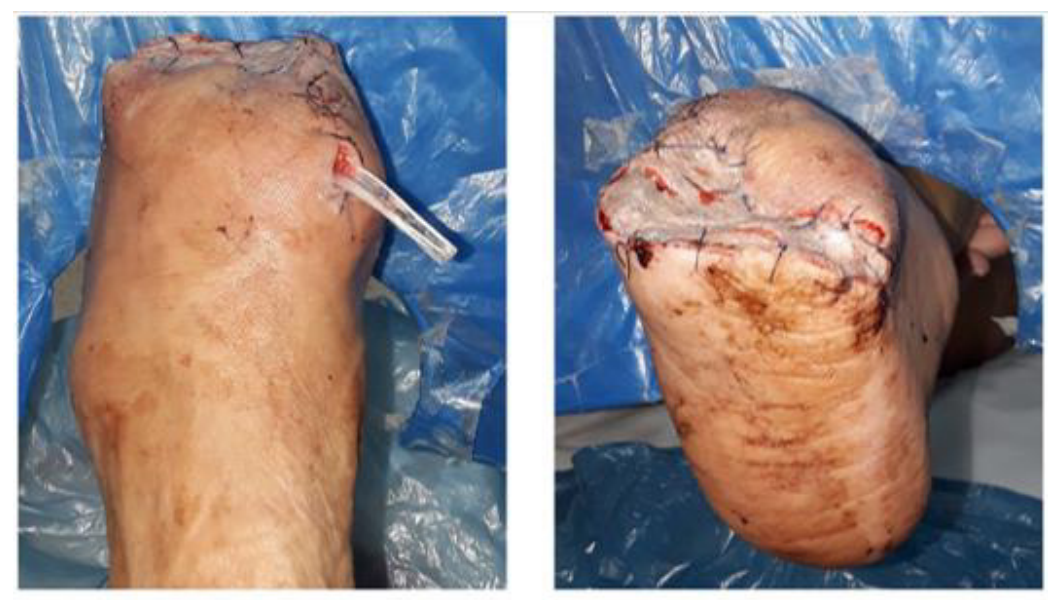

October $10,2020, \pi 1$ POST SURGERY
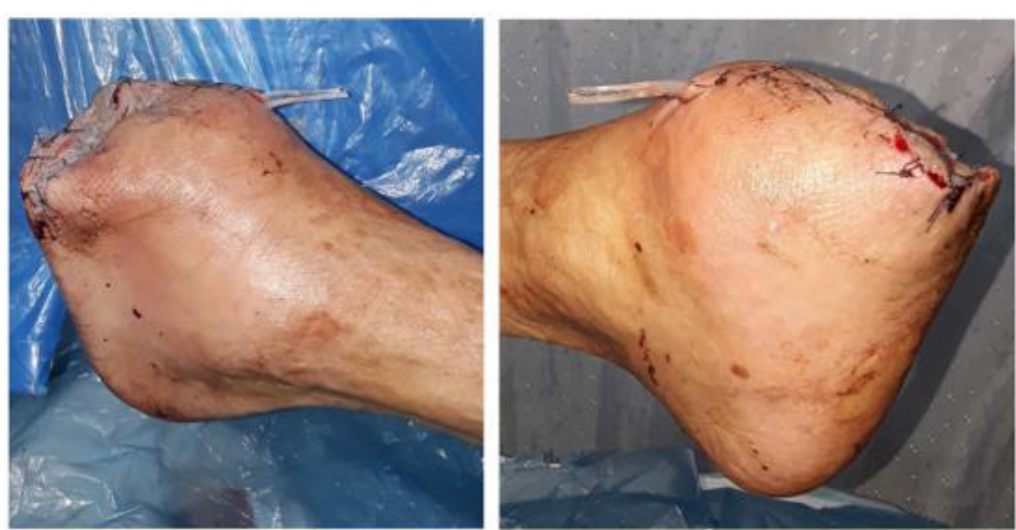

October 10, 2020. J1 POST SURGERY 

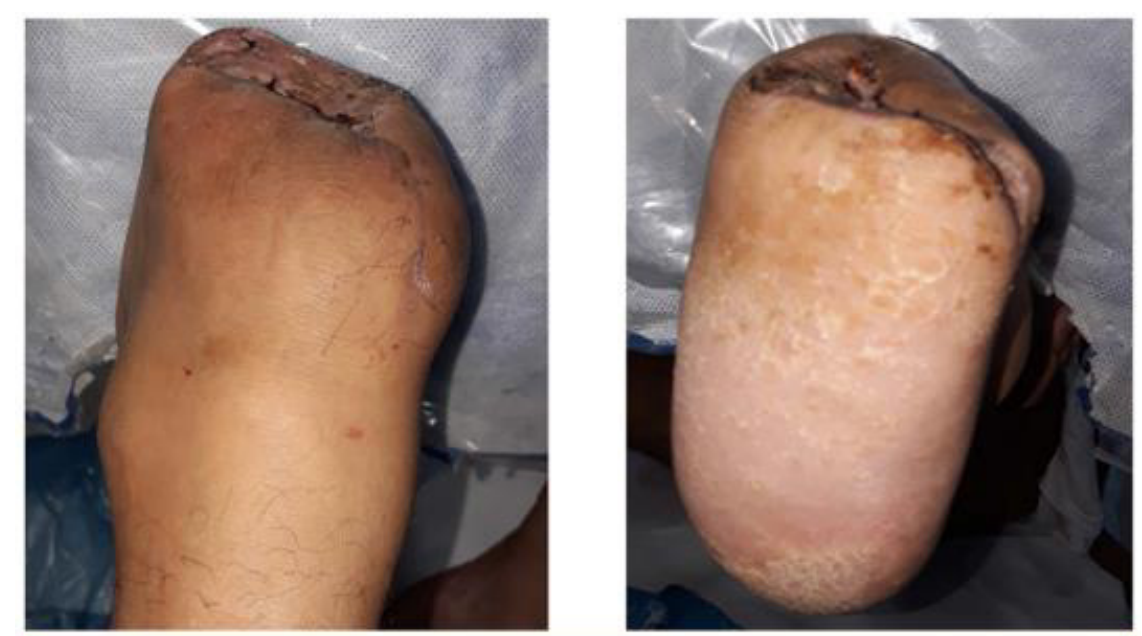

November 16,2020

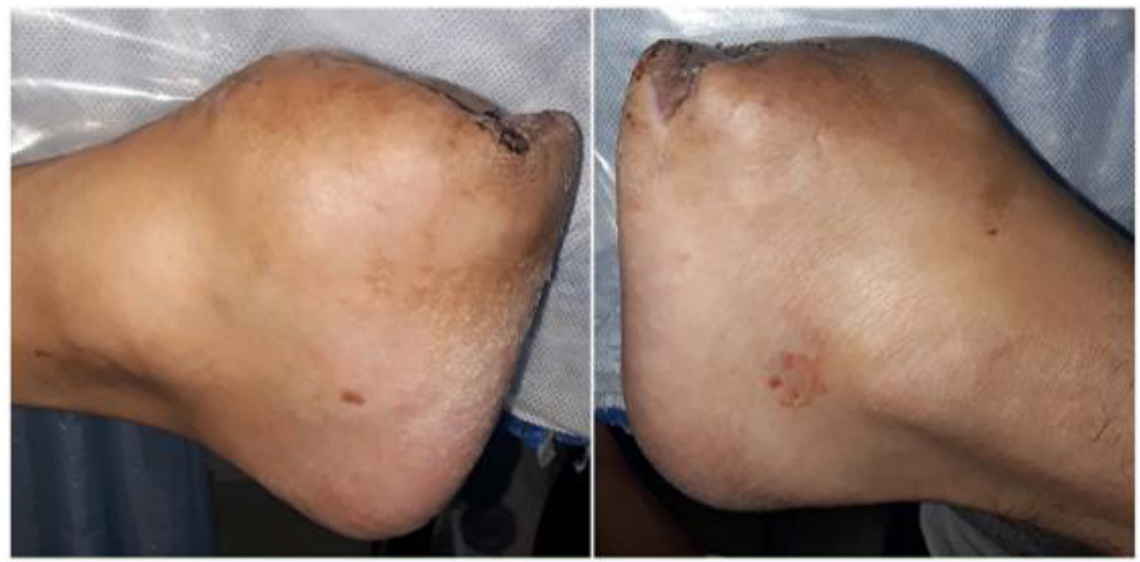

November 16,2020

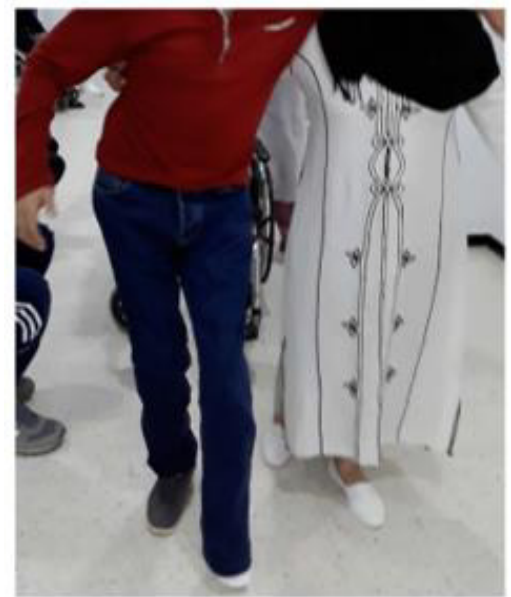

PATIENT RESUMED WALKING

November 16, 2020 

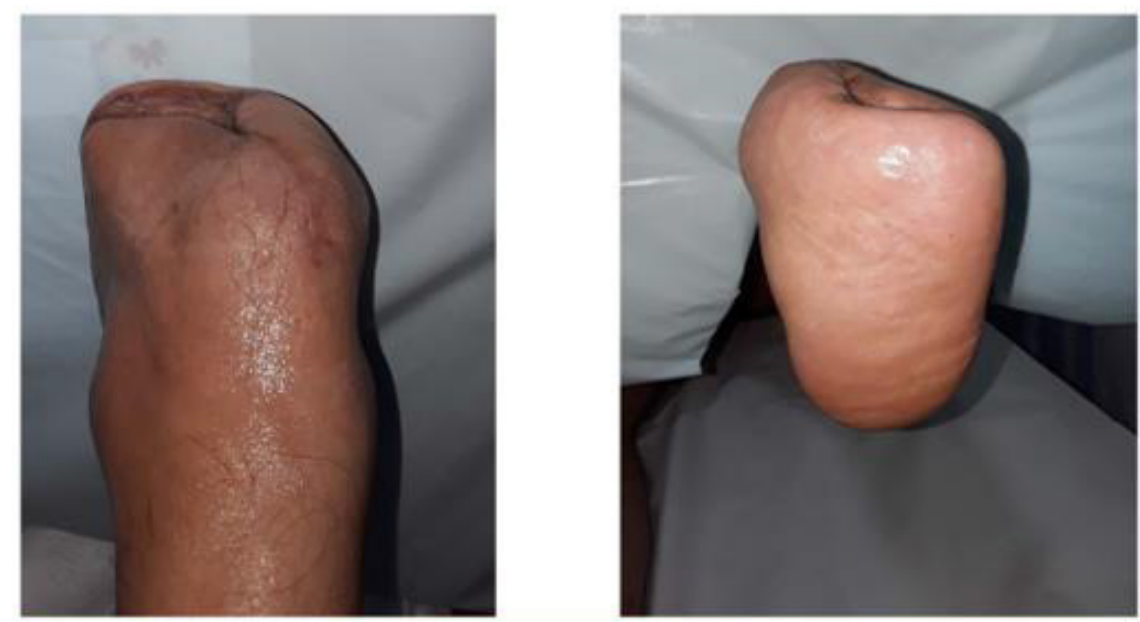

August 14, 2021. - last control
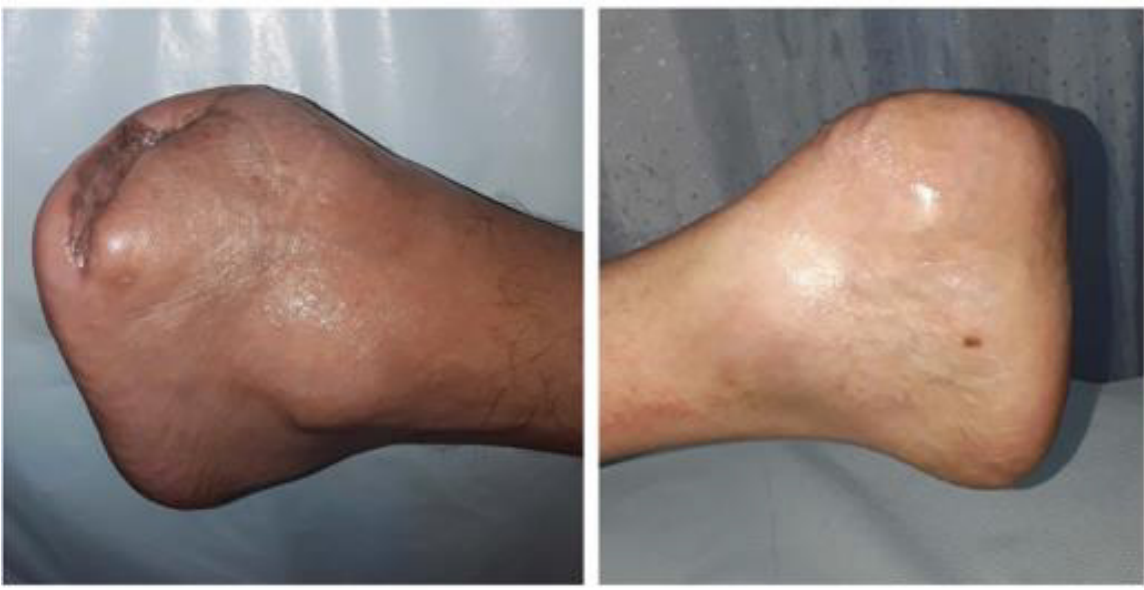

August 14, 2021, - last control

Patient 1.

\section{Patient 2}

Patient: Y..... A.

a. Male

b. Age: 55 ans

c. Type 2 diabetic on insulin

d. Without specific health history

e. No kidney failure

f. HbA1c: $9,20 \%$

g. Platelet count at $568000 / \mathrm{mm}^{3}$, imposing the stopping of Lovenox

h. Put on Aspegic 100 and Lovenox 0.6 for a month while hospitalized for COVID 19.

i. Severe neuropathy of the 4 limbs.
Visit for ischemic necrosis of the left foot, with formal indication of a thigh amputation.

Patient tired from a long hospital stay with a significant imbalance of his diabetes and very stressed by the announcement of the major amputation. We decided to start the treatment while clarifying the risk of major amputation.

\section{Treatment}

Lab analyses and other medical tests:

Arterial and venous Echodoppler which revealed significant Médiacalcose, and :

\section{At the level of the lower left limb:}

a. a thickened wall with limited flow to the popliteal artery

b. a thickened wall with moderately significant stepped strictures in the posterior tibial 
c. incomplete distal thrombosis in the anterior tibial

d. incomplete thrombosis in the foot artery.

\section{At the level of the lower right limb:}

a. significant stenosis, thrombotic distally in the anterior tibial artery

b. incomplete distal thrombosis in the pedal artery.

On the venous level, there is a thrombosis of the distal left internal saphenous vein.

i. PERICAM*

ii. Blood test

iii. Sampling for bacteriological examination.

First session of Carbomedtherapy (Carbon Dioxide Therapy - CDT).

\section{Local care on the left foot:}

a. Foot bath b. BELCIC* creme first followed by Maggot therapy.

c. Use of Leadermax* crème and Maggot Therapy treatment

d. Coconut balm for rehydration

e. Econazole cream for onychomycosis

f. After surgery, ALTRAZEAL* is used in place of BELCIC* and Maggot Therapy treatment.

Broad-spectrum antibiotic therapy at the start, targeted later after the results of the antibiogram.

Physical activity: Active mobilization and complete discharge of the left lower limb with anti-edema position of both limbs.

The evolution has been made towards the delineation of the necrosis both on the surface and in depth, which has allowed us to propose a conservative gesture on the left foot. The surgery act took place on January 09, 2021, a little more than 2 month after the first visit. The procedure consisted of neurectomy of all dead tissue and atypical trans metatarsal amputation.

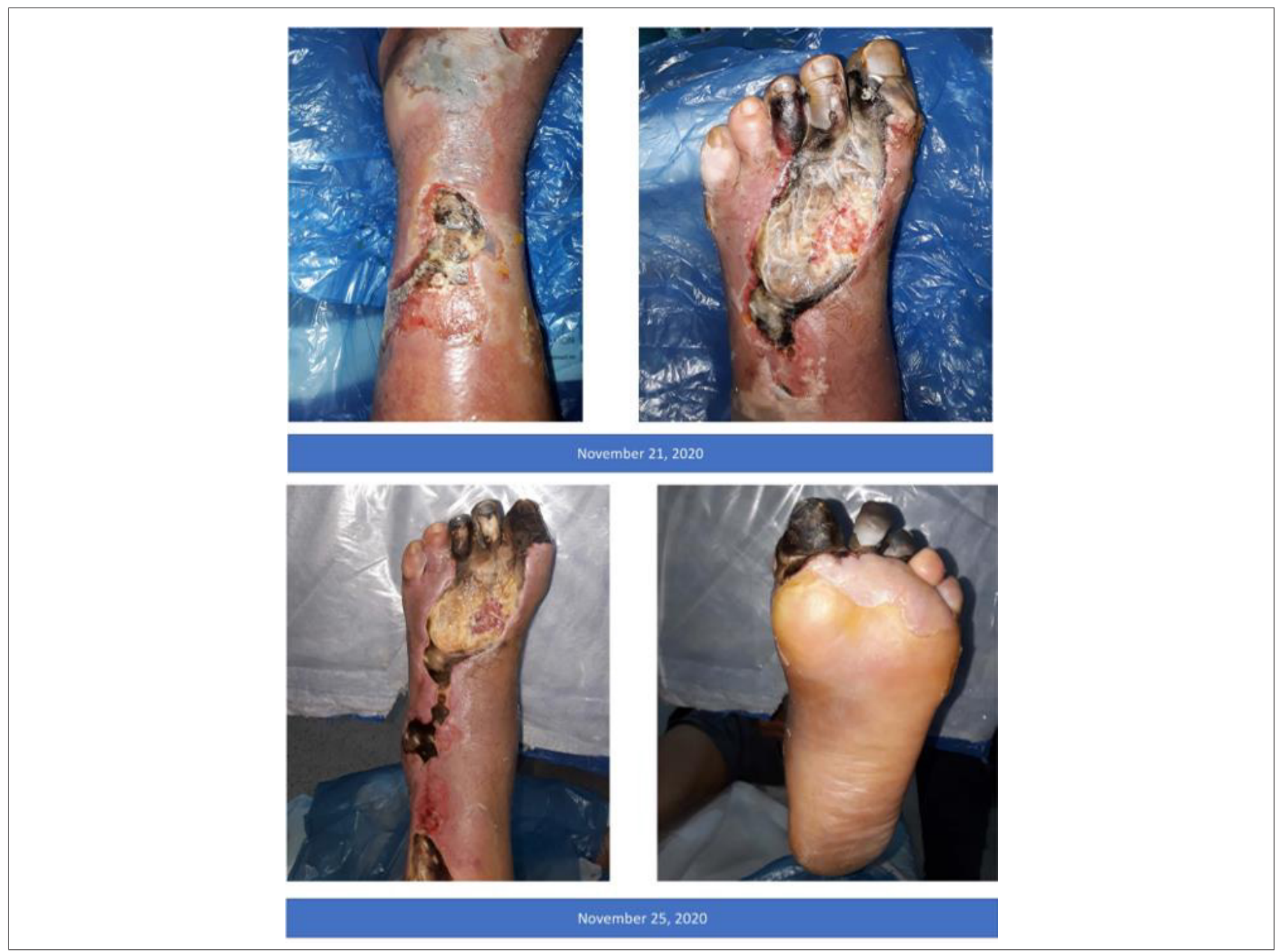



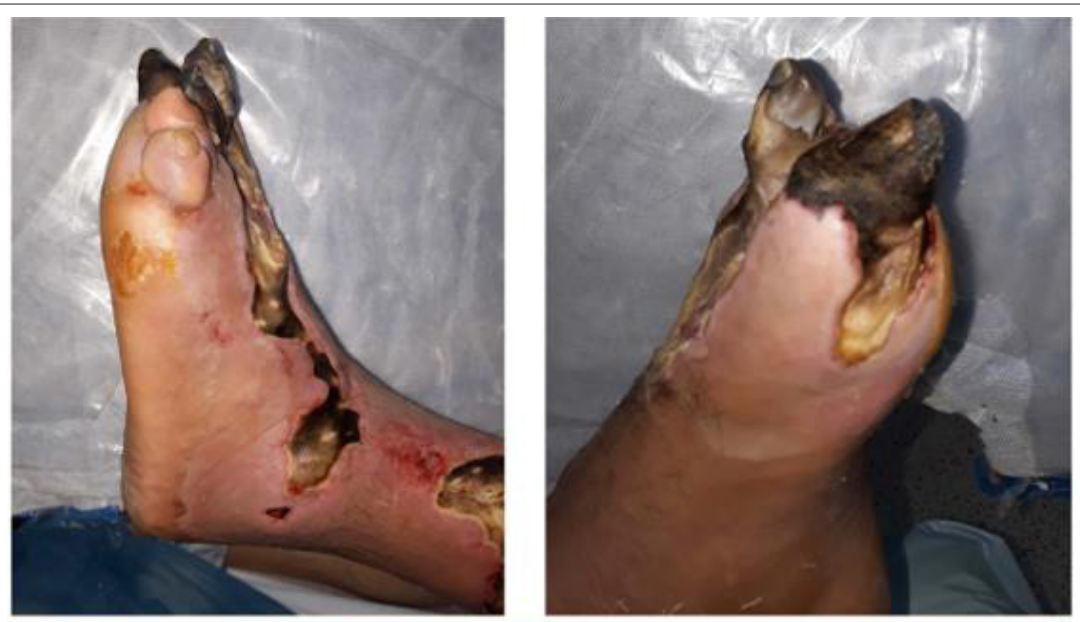

November 25, 2020
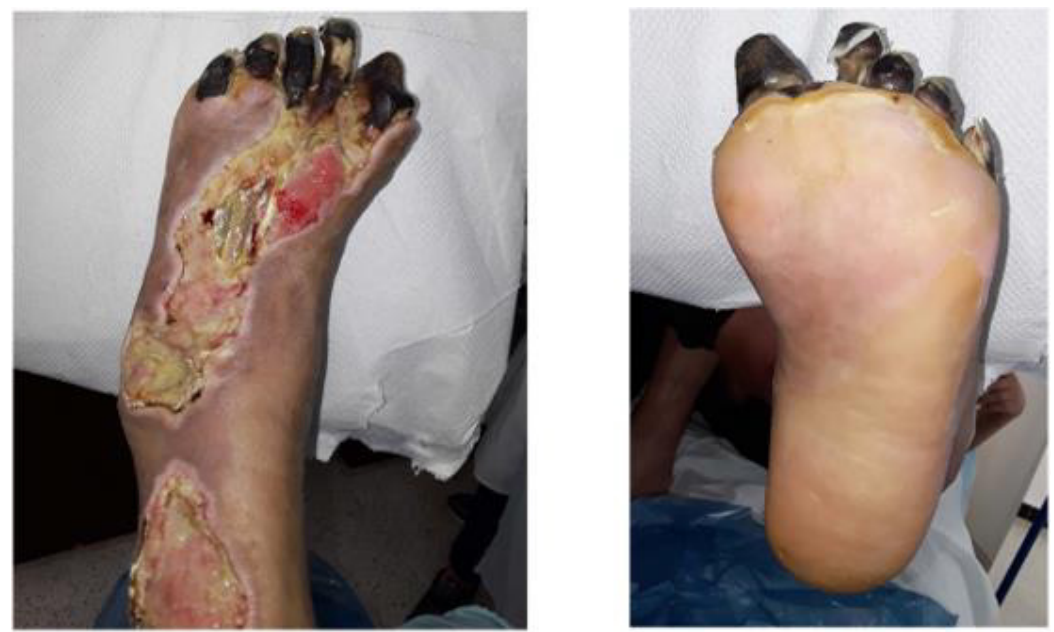

December 19, 2020
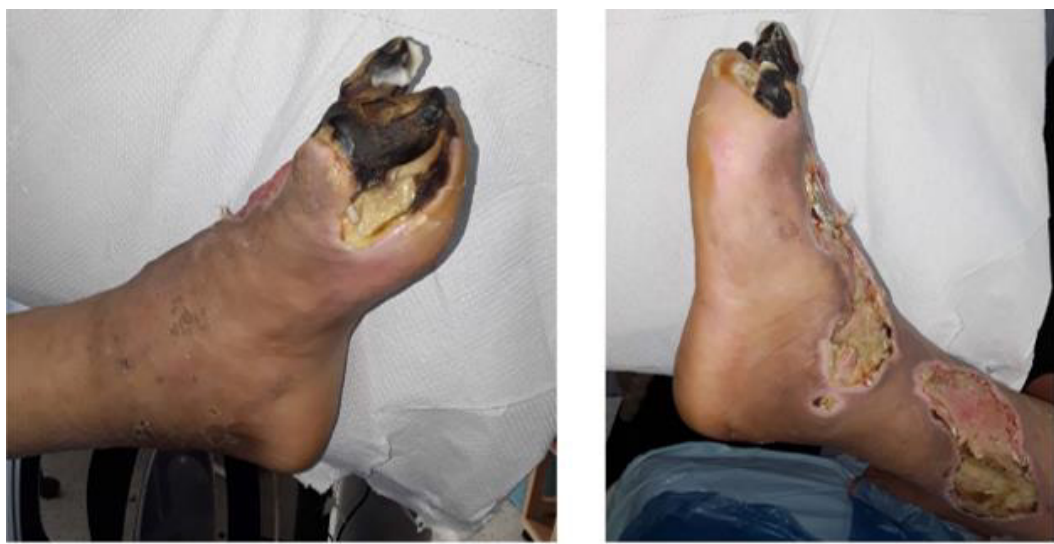

December 19, 2020 

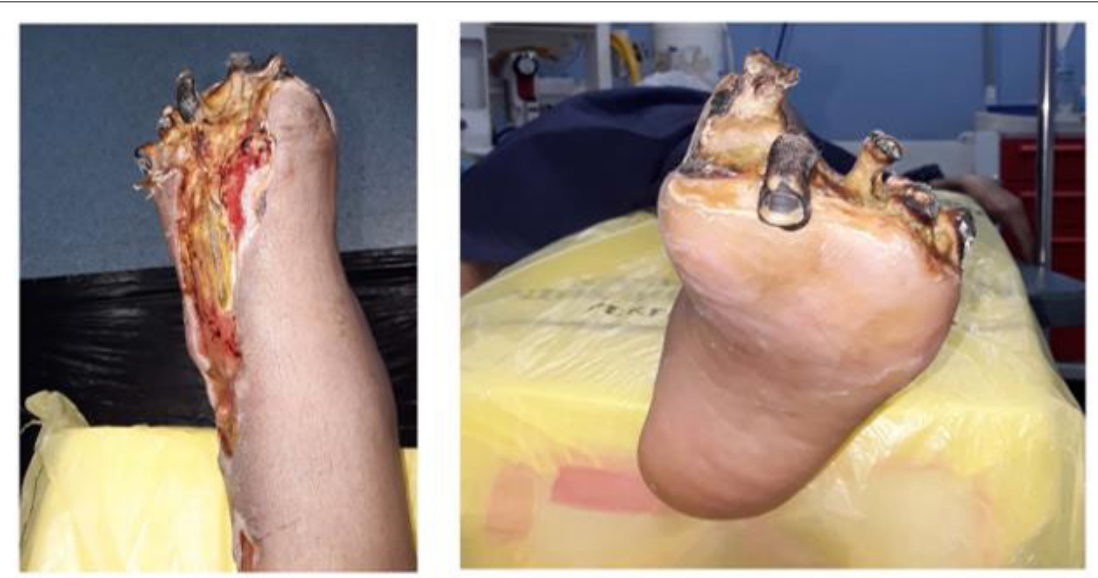

January 09, 2021 - SURGERY DAY -
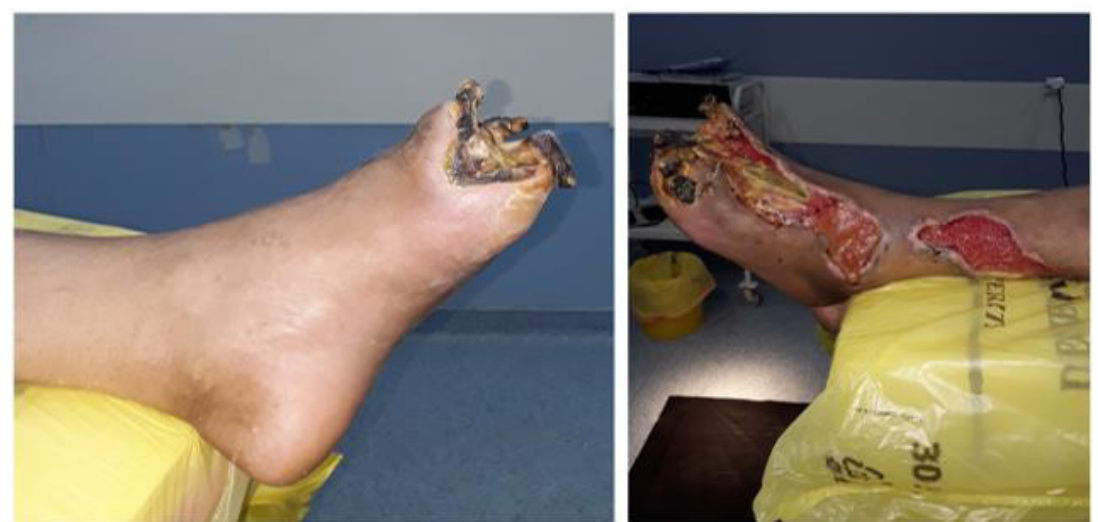

January 09, 2021 - SURGERY DAY -
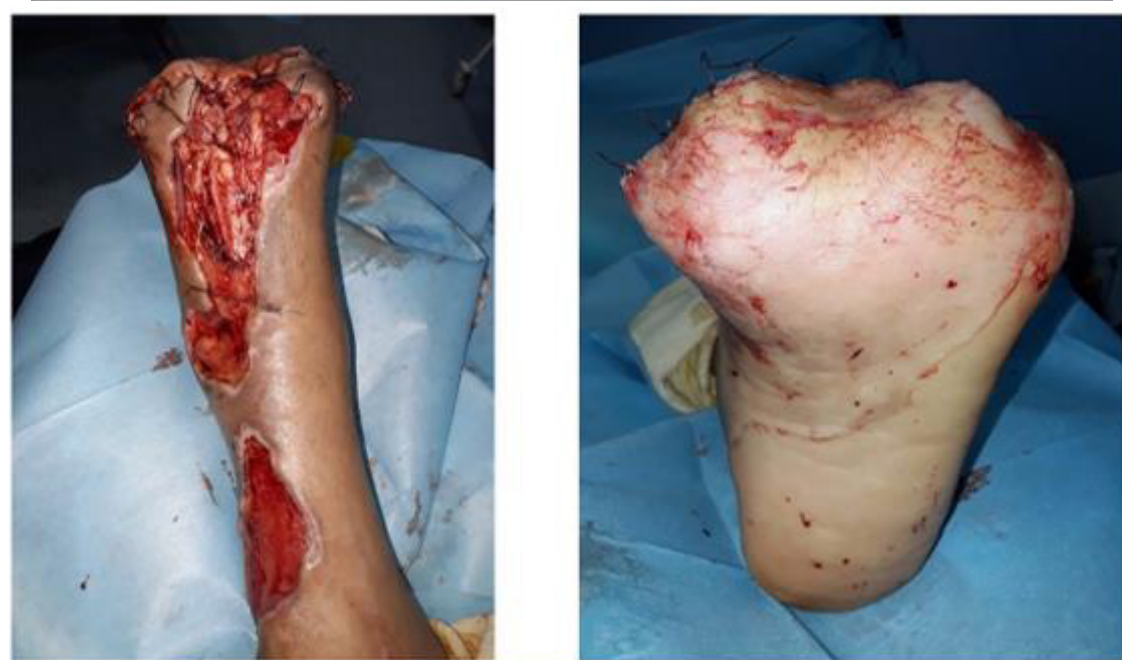

January 09, 2021 - SURGERY DAY - 

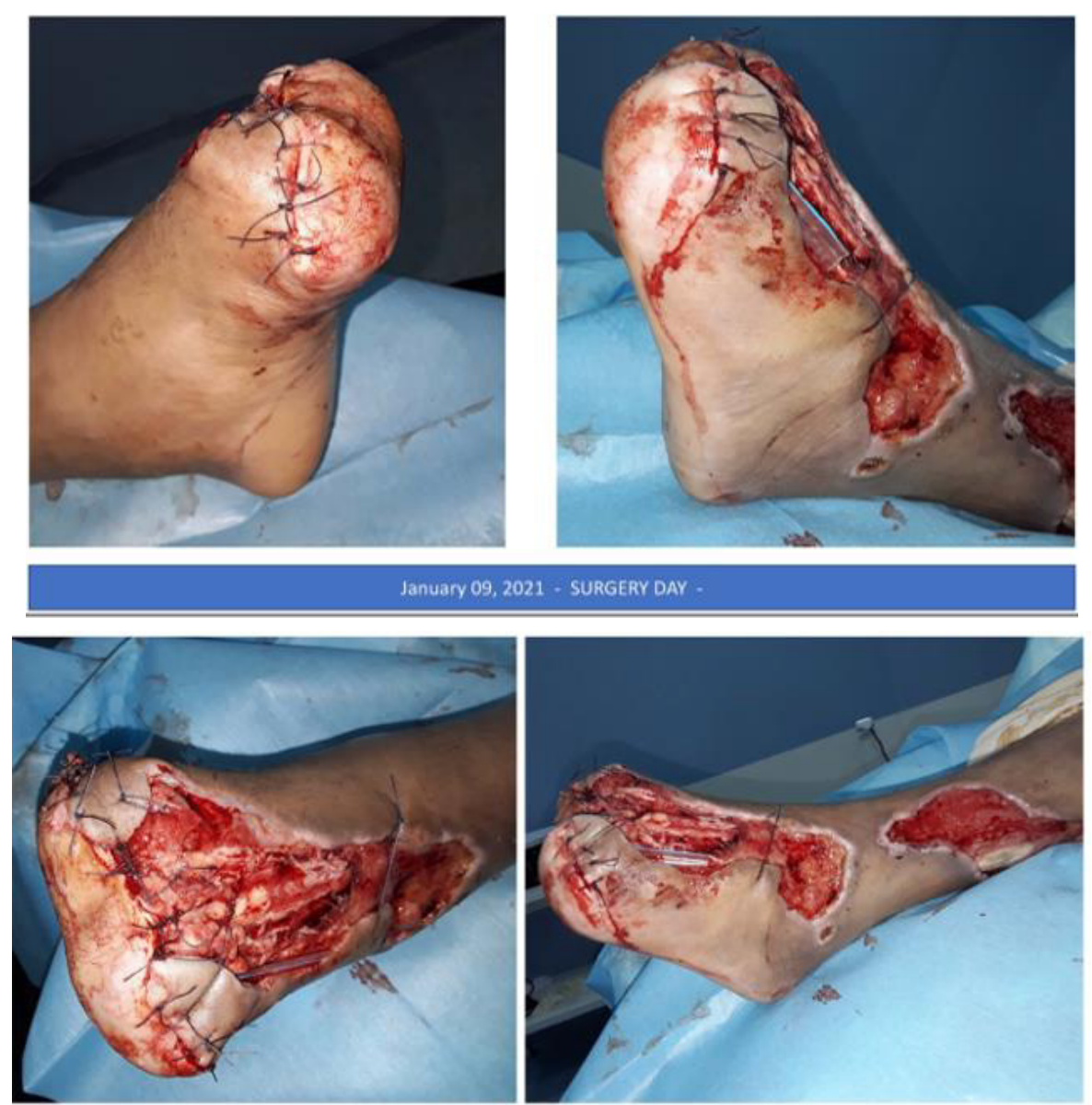

January 09, 2021 - SURGERY DAY -
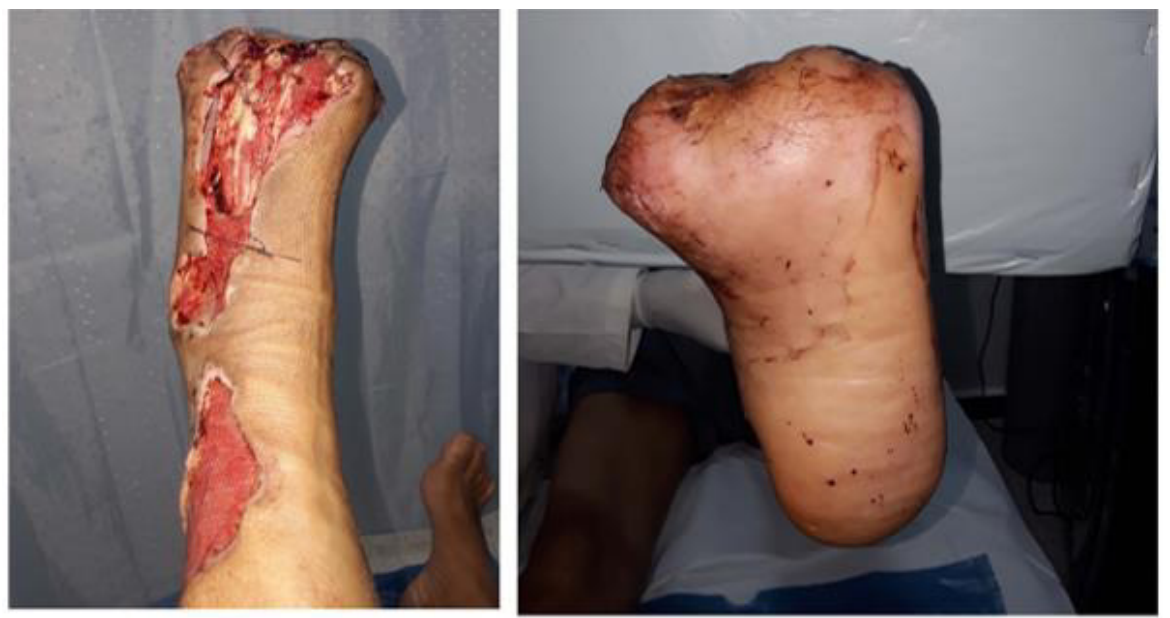

January 09, 2021 - SURGERY DAY 


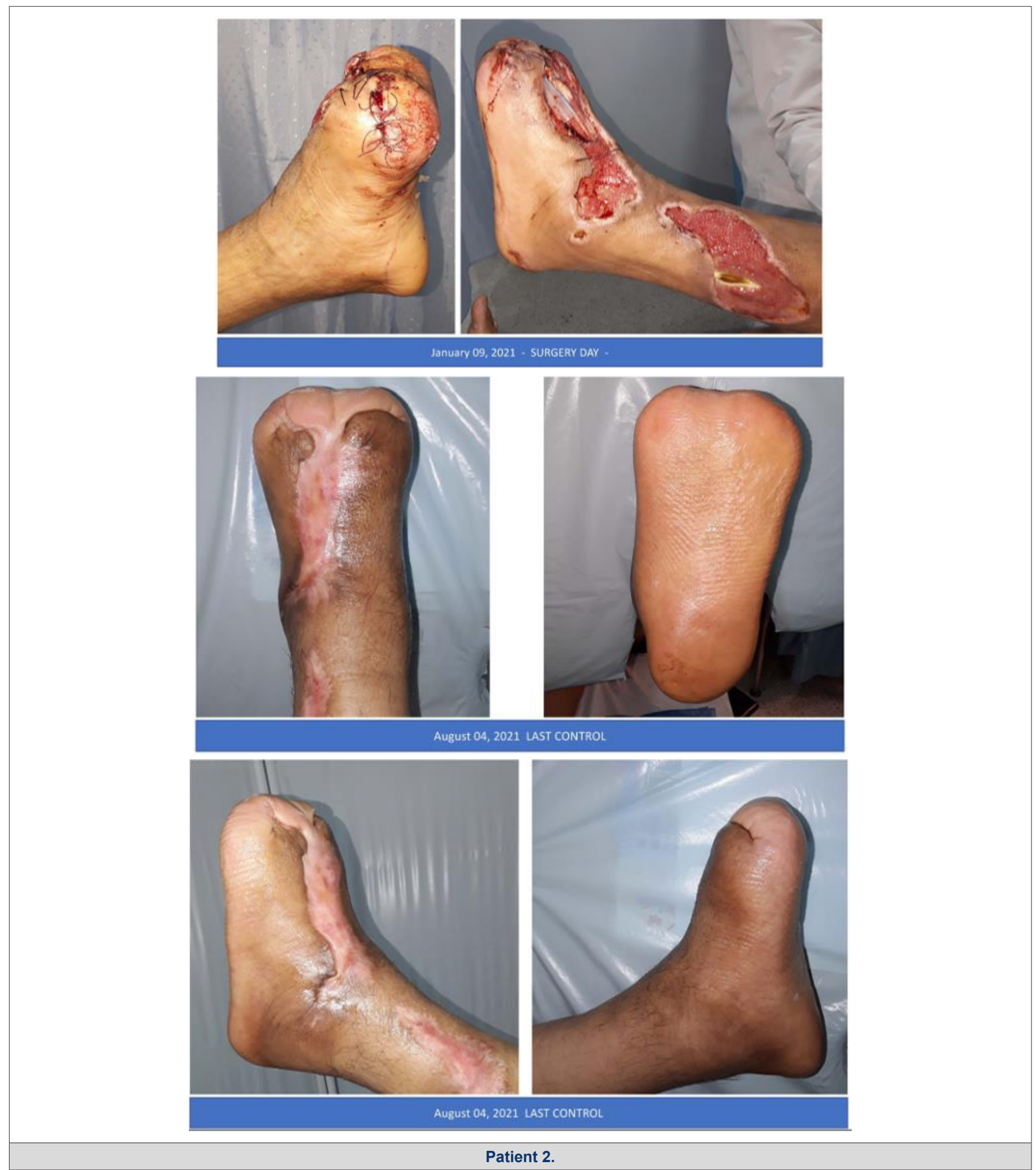

\section{Patient 3}

Patient: M....F

a. Female
b. Age: 41 years old
c. Chronic bronchitis
d. Uterine fibroma under treatment 
e. No kidney failure

f. HbA1c: $5,80 \%$

g. Put under Aspegic 100, Plavix 75, Lovenox 0.8, Sintrom 4mg !!

h. TP a $74,30 \% ? ? ?$

i. INR a 1,30 ???

j. $\quad$ Platelet count at $291000 / \mathrm{mm}^{3}$

k. COVID 19 last month

Visit for ischemia of both feet with a formal indication of amputation in the right thigh. Patient in good general health condition, with no particular health history, who, formally refusing amputation, wished to be treated according to our protocol. We decided to start the treatment while clarifying the risk of major amputation.

\section{Treatment}

Lab analyses and other medical tests:

Arterial and venous Echodoppler:

\section{In the lower right limb:}

a. incomplete thrombosis of the common femoral artery

b. damped flow at the level of the deep femoral artery.

c. Incomplete thrombosis of the upper femoral artery.

d. Incomplete parietal thrombosis of the popliteal artery.

e. incomplete segmental thrombosis in the posterior tibial and the inferior tibial

f. incomplete thrombosis of the pedal artery.

\section{In the lower left limb:}

a. incomplete distal thrombosis of the pedal artery.

b. There is a right and left popliteal deep vein thrombosis with extension towards the ipsilateral external saphenous vein.

i. PERICAM* ii. Blood test

iii. Sampling for bacteriological examination.

\section{First session of Carbomedtherapy (Carbon Dioxide Therapy - CDT).}

\section{Local care on the left foot:}

a. Foot bath

b. BELCIC* creme first followed by Maggot therapy.

c. Use of Leadermax* crème and Maggot Therapy treatment

d. Coconut balm* for rehydration

e. Econazole cream for onychomycosis

f. After surgery, ALTRAZEAL* is used in place of BELCIC* and Maggot Therapy treatment.

Broad-spectrum antibiotic therapy at the start, targeted later after the results of the antibiogram.

Physical activity: Active mobilization and complete discharge of the lower right limb with anti-

edema position of both limbs

The evolution was made towards the delineation of the necrosis both on the surface and in depth, which allowed us to propose a conservative gesture on the right lower limb, the left lower limb being out of danger. The surgery act took place on August 13, 2021, less than 2 months after the first visit.

The procedure consisted of debridement of all necrotic tissue as well as a atypical trans metatarsal amputation, leaving a good plantar support zone in this young woman. We will publish the results of this case at a later date.

In the absence of vascular surgery, it is undeniable that Carbomedtherapy is of considerable benefit. This simple, inexpensive, and very simple apprenticeship technique avoids amputation in patients left with very little or no options at all to avoid losing their autonomy. 

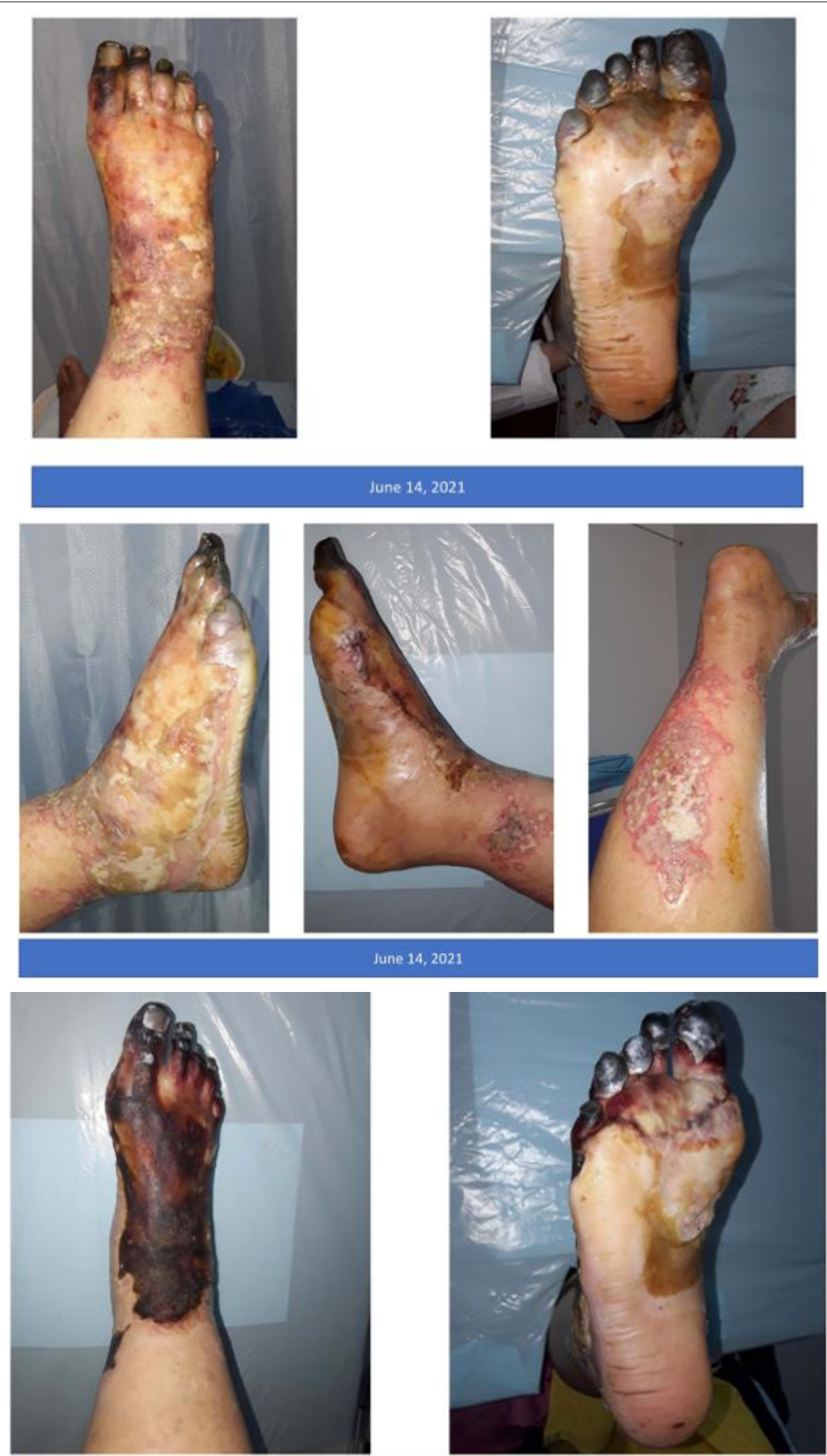

June 19, 2021 

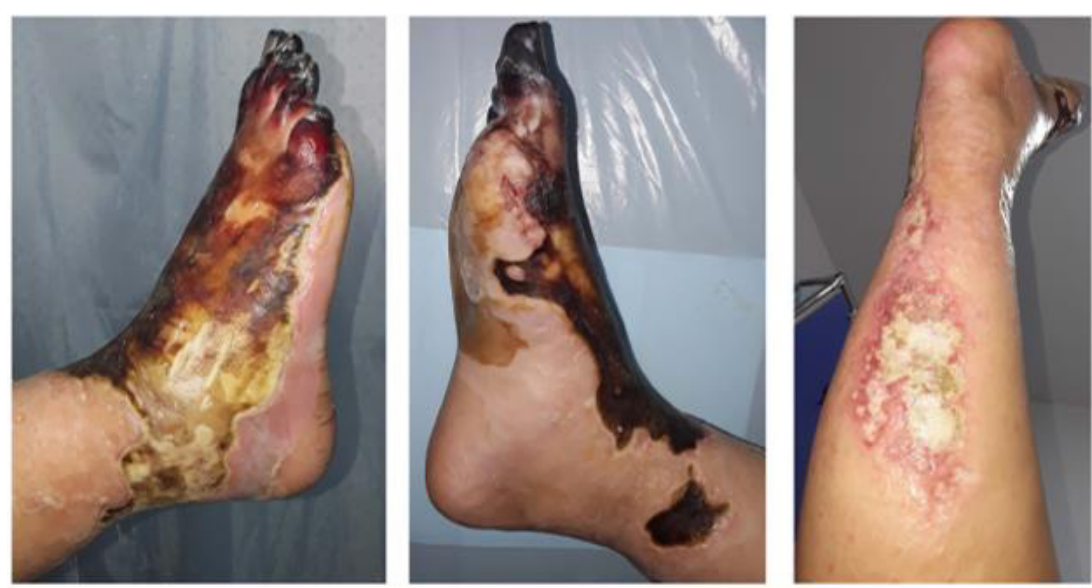

June 19, 2021
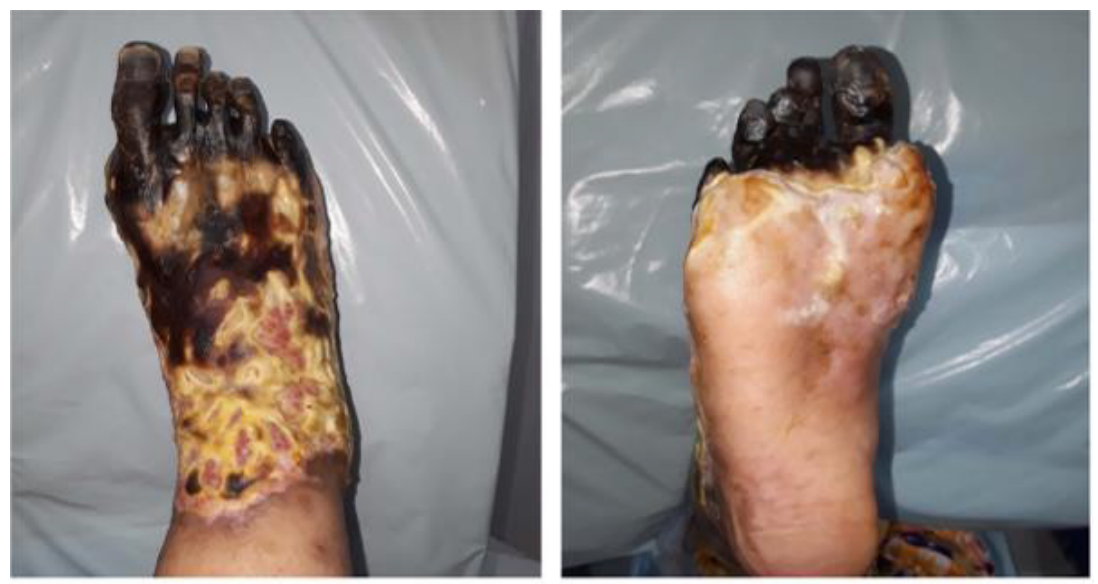

August 07, 2021
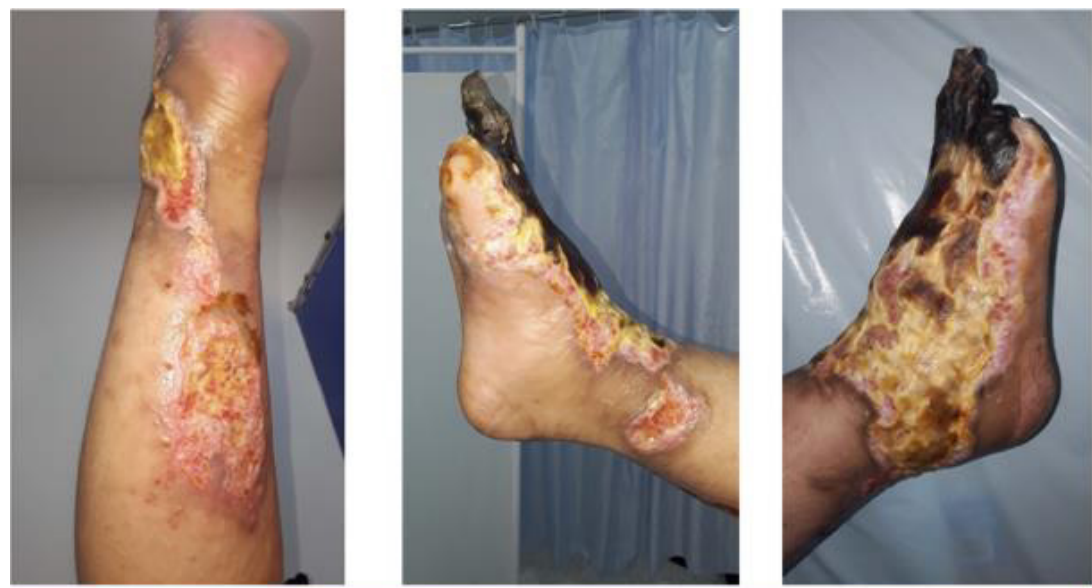

August 07, 2021 

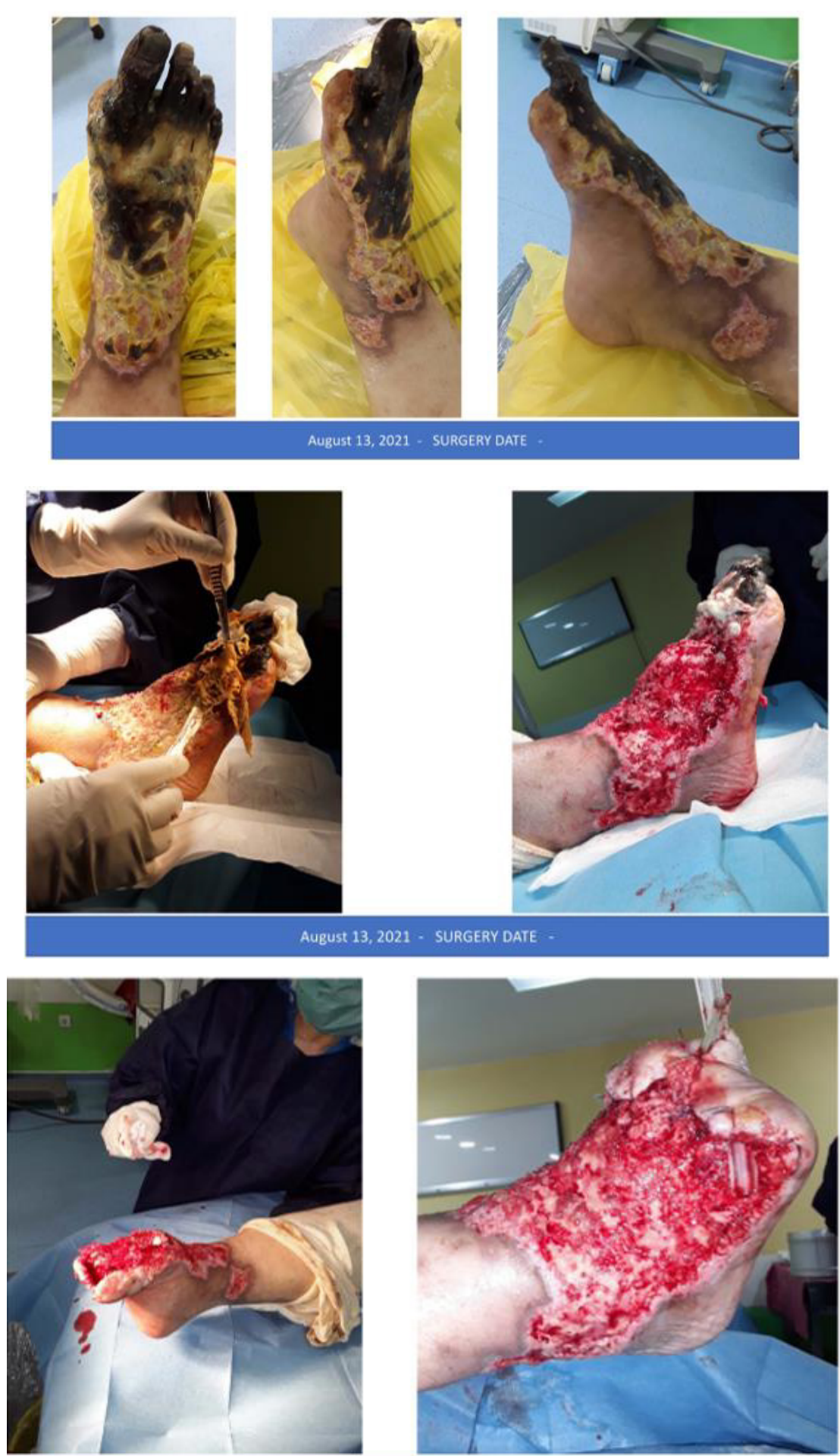

August 13, 2021 - SURGERY DATE 

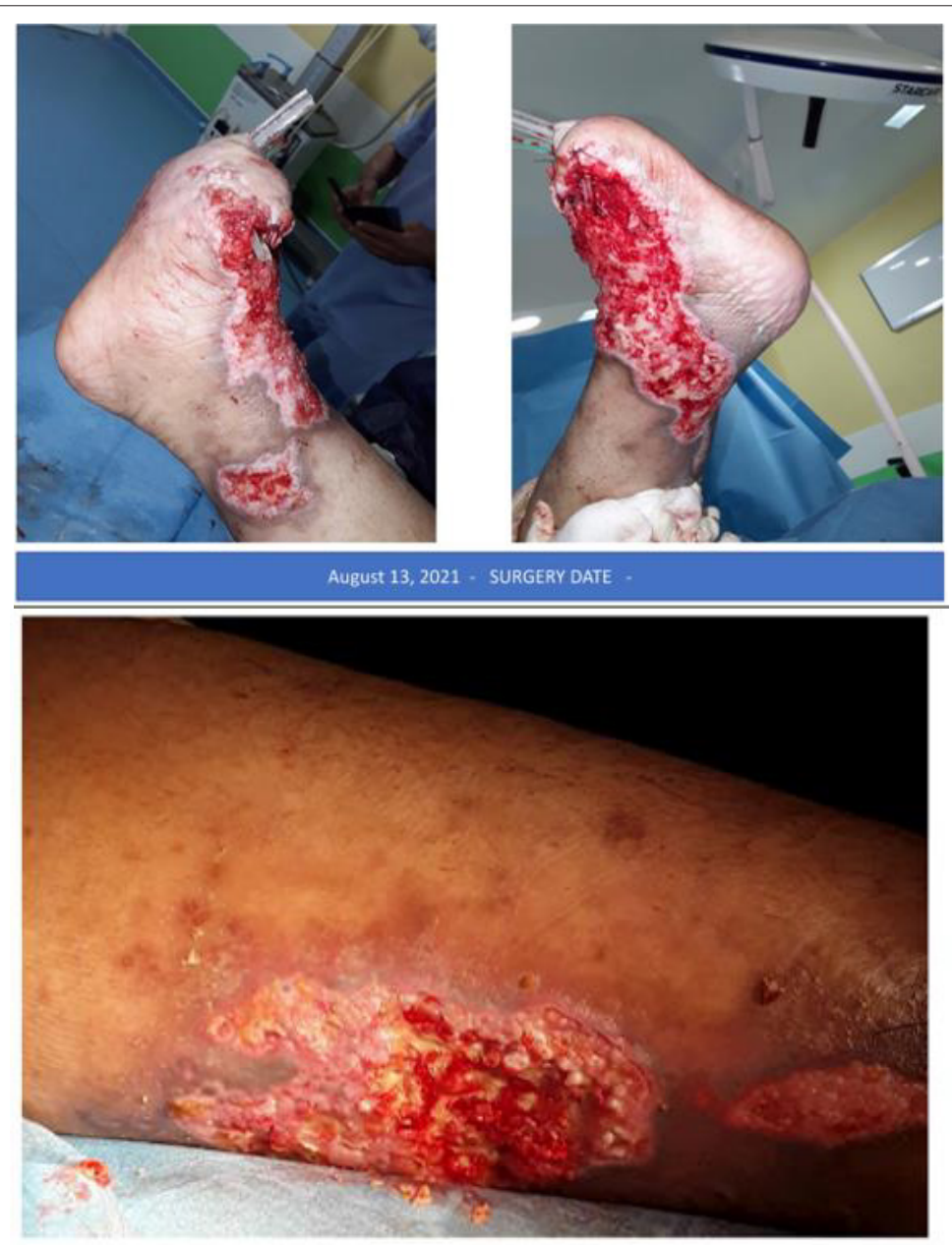

August 13, 2021 - SURGERY DATE -
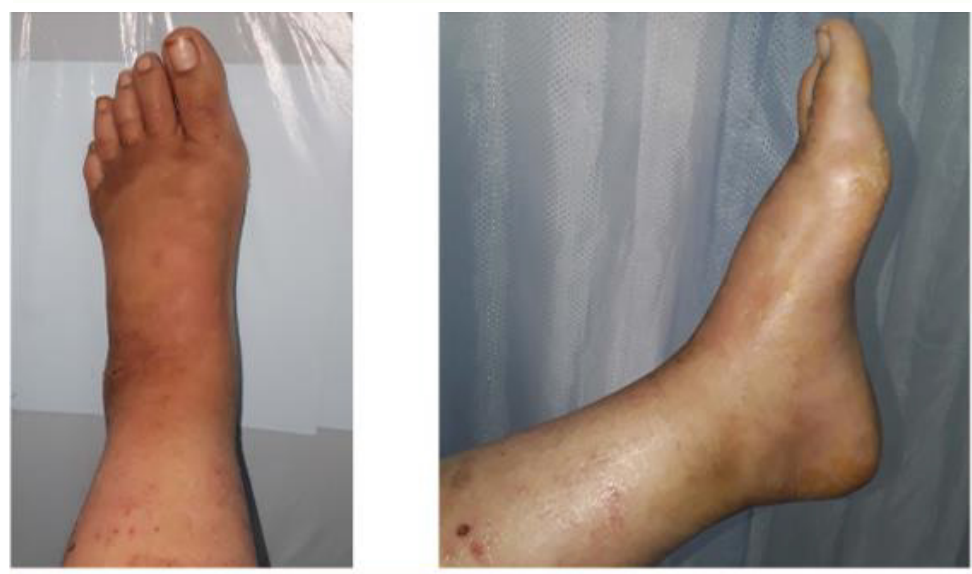

June 14, 2021 

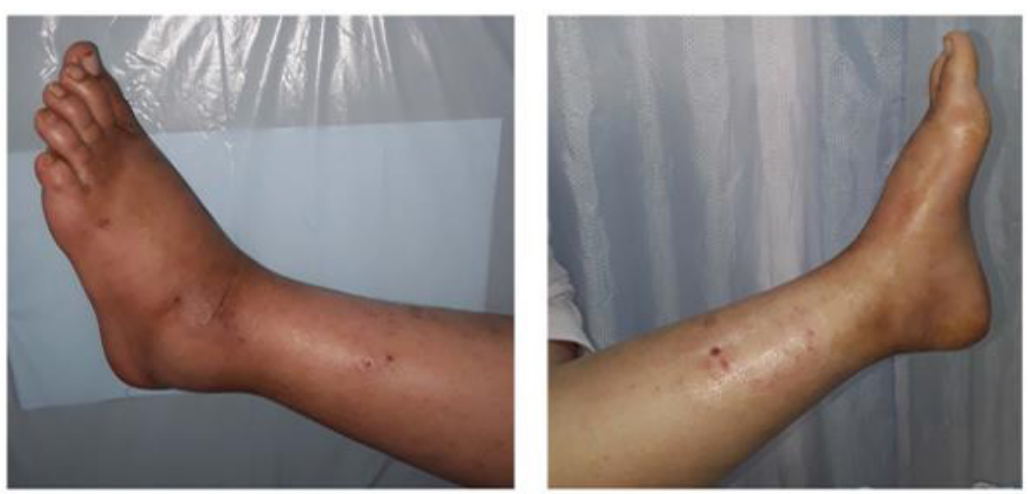

\section{June 14, 2021}

Patient 3.

\section{References}

1. Martini RK, Sherman RA (2003) Maggot debridement therapy. J Bras Med 85: 82-85.

2. Bexfield A, Nigam Y, Thomas S, Ratycliffe NA (2004) Detection and partial characterization of two antibacterial factors from the excretions/ secretions of the medicinal maggot Lucilia sericata and their activity against methicillin-resistant Staphylococcus aureus (MRSA). Microbes Infect $6: 1297-1304$.

3. Marcondes CB (2006) Use of maggot therapy for treating diabetic foot ulcer colonized by mutlidrug resistant bacteria in Brazil. $1^{\text {st }}$ edn. Florianopolis Editora da UFSC, Brazil.

4. McInnes W,RuzehajI N, Wright N, Cowin AJ, Fitridge R (2013) Venous laceration contaminated by multi resistant organisms; Larval therapy \& debridement. J Wound Care 22(suppl 10): s27-30

5. Diabetic Foot Conference abstracts (2017).

6. Boudjenah N (2016) Diabetes and its Complications. Georgia World Congress Center, Atlanta, USA.
7. Boudjenah N (2016) Introduction of Carbomedtherapy Endocrine Practice. Jacksonville 22: 16.

8. Boudjenah A (2013) Diabetic feet: contribution of Carbomedtherapy. Diab Metab 39: A99.

9. Boudjenah N (2020) Diabetic Foot in Algeria. Int J Endocrinol Metab Disord 6(1).

10. Boudjenah N (2016) Introduction of Carbomedtherapy. Endocrine Practice. Pro Quest 22.

11. Boudjenah N (2020) Advocacy for Carbomedtherapy (Carbon Dioxide Therapy) in the Treatment of Diabetic Neuropathy. Int J Endocrinol Metab Disord 6(2).

12. Boudjenah N (2021) Diabetic Foot in Algeria - Gangrene of the Extremities during COVID 19. J Endo Metabol Res 2(1):1-5.

13. Boudjenah N (2021) Diabetic Foot in Algeria - The Debvridement of Wounds - our Attitude. Am J Biomed Sci \& Res 13(5).

14. Boudjenah N (2021) Diabetic Foot in Algeria - Illustration II. 